Central Washington University

ScholarWorks@CWU

All Faculty Scholarship for the College of the Sciences

3-18-2004

Detection of arbitrarily large dynamic ground motions with a dense high-rate GPS network

Yehuda Bock

Linette Prawirodirdjo

Timothy I. Melbourne

Follow this and additional works at: https://digitalcommons.cwu.edu/cotsfac

Part of the Geomorphology Commons, Geophysics and Seismology Commons, and the Tectonics and Structure Commons 


\title{
Detection of arbitrarily large dynamic ground motions with a dense high-rate GPS network
}

\author{
Yehuda Bock and Linette Prawirodirdjo \\ Cecil H. and Ida M. Green Institute of Geophysics and Planetary Physics, Scripps Institution of Oceanography, La Jolla, \\ California, USA
}

Timothy I. Melbourne

Department of Geological Sciences, Central Washington University, Ellensburg, Washington, USA

Received 24 November 2003; revised 27 January 2004; accepted 4 February 2004; published 18 March 2004.

[1] We describe the detection of teleseismic surface waves from the 3 November $2002 \mathrm{Mw} 7.9$ Denali fault earthquake in Alaska with a dense network of $1 \mathrm{~Hz}$ GPS stations in southern California, about $3900 \mathrm{~km}$ from the event. Relative horizontal displacements with amplitudes in excess of $15 \mathrm{~mm}$ and duration of 700 seconds agree with integrated velocities recorded by nearby broadband seismometers with an $\mathrm{rms}$ difference of $2-3 \mathrm{~mm}$. The displacements are derived from independent $1 \mathrm{~Hz}$ instantaneous positions demonstrating that a GPS network can provide direct measurements of arbitrarily large dynamic and static ground horizontal displacements at periods longer than $1 \mathrm{~s}$ and amplitudes above $2 \mathrm{~mm}$, with an inherent precision (signal to noise) that improves indefinitely with amplitude without clipping and in real time. High-rate, real-time GPS networks can enhance earthquake detection and seismic risk mitigation and support other applications such as intelligent transportation and civil infrastructure monitoring. INDEX TERMS: 1242 Geodesy and Gravity: Seismic deformations (7205); 1294 Geodesy and Gravity: Instruments and techniques; 7212 Seismology: Earthquake ground motions and engineering; 7294 Seismology: Instruments and techniques; 7205 Seismology: Continental crust (1242). Citation: Bock, Y., L. Prawirodirdjo, and T. I. Melbourne (2004), Detection of arbitrarily large dynamic ground motions with a dense high-rate GPS network, Geophys. Res. Lett., 31, L06604, doi:10.1029/2003GL019150.

\section{Introduction}

[2] GPS geodesy and seismology have traditionally been considered distinct tools focused on disparate frequency bands of the deformation spectrum. The former has been largely concerned with long-term secular tectonic deformation and static displacements from large earthquakes, while the latter measured dynamic displacements with periods ranging from fractions of seconds to several minutes. Continuous GPS (CGPS) in particular has proven very effective in the accurate measurement of interseismic, coseismic, and postseismic deformation, and dense networks such as the Southern California Integrated GPS Network (SCIGN) are now routinely deployed at active plate boundaries. As GPS precision and methodologies have improved there has occurred a gradual merging of

Copyright 2004 by the American Geophysical Union. 0094-8276/04/2003GL019150 the detection spectra of geodesy and seismology, and in particular GPS accuracy and spectral sensitivity has been pushed steadily towards measuring dynamic transients previously accessible only with the tools and sensors of seismology. CGPS has detected aseismic slow earthquakes [e.g., Dragert et al., 2001; Melbourne et al., 2002] and precursory transient slip [Melbourne and Webb, 2002] not detected by traditional seismic methods. The capabilities of CGPS in sensing static and slow deformations explains why it has been chosen as a fundamental tool for the Plate Boundary Observatory (PBO) [Silver et al., 1999], the geodetic component of the U.S. Earthscope project.

[3] The use of CGPS as a seismic tool, however, has not been fully exploited either by PBO or USArray, the seismic component of Earthscope, despite growing evidence of the utility of these data. Nikolaidis et al. [2001] used the technique of instantaneous GPS positioning [Bock et al., 2000] to demonstrate that SCIGN stations were able to detect dynamic as well as static displacements caused by the 16 October 1999, $M w 7.1$ Hector Mine earthquake. The $30 \mathrm{~s}$ sampling interval of the SCIGN stations at that time precluded a more detailed examination but demonstrated that CGPS showed great promise for expanding the available frequency range of modern seismic instrumentation. In response an effort was initiated to upgrade SCIGN sites to high-rate $(1 \mathrm{~Hz}$, instead of $30 \mathrm{~s})$ sampling and low-latency (1 s, instead of $86400 \mathrm{~s})$ data collection, analysis and dissemination. The first realization of this effort is the Orange County Real Time Network (OCRTN) (Figure 1), which has been operating since June 2002 and serving GPS data to land surveyors in real time [Andrew, 2003]. The latency from CGPS instrument to client is $1-2 \mathrm{~s}$ over a wireless link (cell modem) and $0.5 \mathrm{~s}$ over a direct Internet link. Real-time instantaneous positioning of the $1 \mathrm{~Hz}$ GPS data is routinely performed.

[4] Larson et al. [2003] used $1 \mathrm{~Hz}$ GPS measurements at individual sites in Alaska and across North America to detect seismic waves generated by the Denali fault $M w 7.9$ earthquake, 3 November 2002, 22:12:41 (day-of-year 307) in central Alaska at a depth of about $5 \mathrm{~km}$ with epicenter at $63.74^{\circ} \mathrm{N} 147.69^{\circ} \mathrm{W}$ [e.g., Eberhart-Phillips et al., 2003]. The first opportunity to measure strong ground motions with the OCRTN was also provided by the Denali fault earthquake at a distance of more than $3900 \mathrm{~km}$. In this paper we describe the measurement of teleseismic surface waves caused by this earthquake. Approximate co-location of broadband seismic and CGPS instruments allows us for 


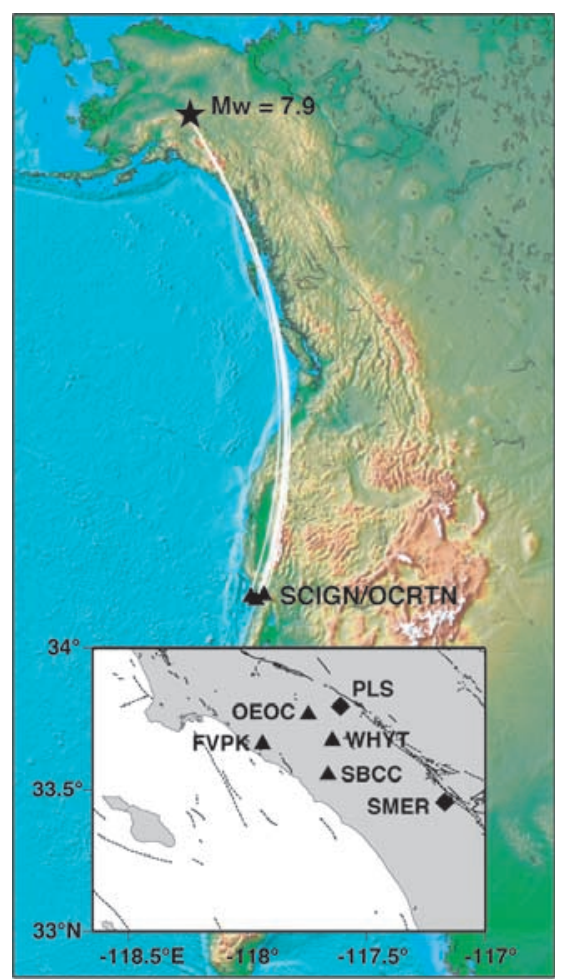

Figure 1. Location of the $2002 \mathrm{Mw} 7.9$ Denali fault earthquake epicenter in Alaska with respect to the SCIGN/ OCRTN (GPS) sites in southern California (http:// www.scign.org/), and seismic raypaths (about $3900 \mathrm{~km}$ ). The inset shows the location of the 4 GPS sites (triangles) and 2 broadband seismic stations (diamonds) used in this study. Site PLS is part of TriNet (http:// www.trinet.org/data.html\#wave;http://www.scecdc.scec. org/waveforms.html) and site SMER is part of ANZA (http://eqinfo.ucsd.edu/projects/anza/index.html; http:// eqinfo.ucsd.edu/index.html).

the first time to characterize and assess the accuracy of displacements measured directly by a dense CGPS network by comparing with displacements derived from integrating the broadband velocity data. Taking advantage of the density of the OCRTN we are able to reduce the noise in the resulting displacements and improve on the methodology outlined by Bock et al. [2000] and implemented by Nikolaidis et al. [2001] for the Hector Mine earthquake. We demonstrate that high-rate $(1 \mathrm{~Hz}$ or greater) dense GPS networks can directly measure arbitrarily large dynamic and static ground motions with very low latency (seconds) without clipping.

\section{CGPS Data Analysis}

[5] The ability to resolve integer-cycle phase ambiguities with only a single epoch of GPS data is what distinguishes instantaneous GPS positioning from static GPS and real time kinematic (RTK) methods, which require multiple epochs to resolve and maintain phase continuity. Instantaneous GPS provides an independent position at each observation epoch, at the receivers' sampling rate. The noise sources and noise characteristics of single-epoch (30 s) positions and many-epoch positions derived by averaging instantaneous GPS positions over a range of time intervals have been described in detail in Bock et al. [2000] and Nikolaidis et al. [2001] in both the temporal and frequency domains, for a range of intersite distances, and for horizontal and vertical components. Spectral analysis of the OCRTN data confirms that the noise of $1 \mathrm{~Hz}$ instantaneous positions have the same flicker noise characteristics as 24-hour static solutions and $30 \mathrm{~s}$ instantaneous positions. Spectral and covariance analysis of a 90-day span of $1 \mathrm{~Hz}$ positions from the similarly equipped and dense Parkfield real-time CGPS network also indicates flicker noise characteristics at the higher frequencies (J. Langbein, personal communication, 2003). Based on these data we expect to be able to detect horizontal displacements with a single-epoch (one-sigma) precision of about $6 \mathrm{~mm}$ and vertical displacements with a single-epoch precision of $40 \mathrm{~mm}$. We should therefore be able to resolve with the OCRTN data the horizontal components of the Rayleigh and (perhaps) Love waves from the Denali fault earthquake, but not the vertical displacements, which are about an order of magnitude smaller due to the strike slip nature of the earthquake. We focus, therefore, on the detection of horizontal motions.

[6] The goal of our analysis is to provide $1 \mathrm{~Hz}$ position horizontal site displacements with respect to an Earthcentered, Earth-fixed reference frame ITRF2000 [Altamimi et al., 2002], and to compare these to displacements derived from velocities measured at nearly-colocated broadband seismic stations. We are able to estimate accurate ITRF2000 positions of all sites in the network on the day of the earthquake as a result of a model fit to the position time series estimated daily using static positioning of 24-hour batches of $30 \mathrm{~s}$ GPS observations by the Scripps Orbit and Permanent Array Center (http://sopac.ucsd.edu/processing/ coordinates) for a large number of global and regional continuous GPS sites, including the OCRTN sites. The model includes rate terms (site velocities), coseismic and postseismic deformation, annual and semi-annual fluctuations, and instrumental offsets. The modeled daily ITRF2000 static positions have a horizontal precision (one-sigma) of about $1 \mathrm{~mm}$ and a vertical precision of about $3 \mathrm{~mm}$ and hence provide an accurate absolute datum with respect to which the seismic motions can be estimated. This is important since some of the OCRTN sites are subject to large seasonal fluctuations ( $20 \mathrm{~mm}$ amplitudes) due to groundwater effects. However, the technique of instantaneous positioning provides only relative positions of the network stations with respect to the known location of one of the sites in the network. Here the position of one site (WHYT) was held fixed to its expected static value on that day while the other OCRTN sites were only loosely constrained $(100 \mathrm{~m})$ to their expected static values. Site WHYT was also displaced by the seismic motions caused by the Denali fault earthquake so that the displacements at the other sites are biased by this neglected motion.

[7] Next we performed sidereal filtering of the $1 \mathrm{~Hz}$ GPS positions based on the position time series for the two days prior to the earthquake to reduce by about $50 \%$ signal multipath and other diurnally repeating noise sources as described by Bock et al. [2000] and implemented by Nikolaidis et al. [2001]. These effects are due to the nominal 12-hour orbital periods of the GPS satellites that result in the satellite constellation passing over the same point on the 


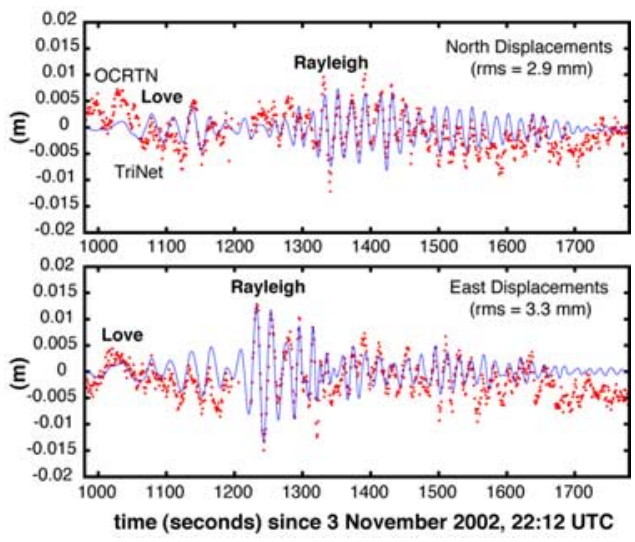

Figure 2. Comparisons of displacements of GPS site OEOC and the nearby TriNet seismic site PLS, in north and east directions. See Figure 1 for the location of sites. The horizontal axis denotes seconds after the Denali fault earthquake (3 November 2002, 22:12), and the vertical scale denotes displacement (in meters). The seismic wave was felt in Orange County about 1000 seconds after the event. The duration of shaking (Love and Rayleigh waves) was about $700 \mathrm{~s}$ with peak amplitude of about $15 \mathrm{~mm}$. The rms differences between the GPS and seismic displacements are shown in each plot. The GPS displacements are the result of sidereal filtering using the two days prior to the day of the earthquake as explained in the text. The thirty $1 \mathrm{~Hz}$ GPS positions missing at about 1200 seconds after the event are the result of missing data at OEOC on the day prior to the earthquake (no data were missing on the day of the earthquake) and the process of sidereal filtering.

Earth's surface at a sidereal period (86164 seconds). In this paper, we take advantage of the density of the GPS network to further reduce the noise in the resulting single-epoch displacements by spatial filtering, as is common procedure in the analysis of regional GPS networks. Specifically, we stacked the $1 \mathrm{~Hz}$ positions of three OCRTN sites (FVPK, OEOC, SBCC (Figure 1)) to further reduce the noise in the GPS-estimated displacements.

\section{Comparison With Seismic Displacements}

[8] We performed time alignment of the $1 \mathrm{~Hz}$ position time series of GPS site SBCC with respect to OEOC and FVPK, by shifting the OEOC positions by 12 seconds in order to take into account the extra path travelled by the teleseismic waves. Likewise, we needed to shift the seismic displacements at SMER by 16 seconds.

[9] To validate the resulting $1 \mathrm{~Hz}$ GPS displacements, we compared the solutions with positions derived from two nearby broadband (Streckheisen STS-2) seismometers (PLS and SMER (Figure 1)) deployed as part of the TriNet and Anza seismic networks in southern California. To convert the raw seismic recordings to displacements, we integrated raw velocity records after accounting for instrument response. Raw velocity recordings from the two Streckheisen STS-2 instruments were integrated directly without deconvolution of instrument responses, since the response of an STS-2 is flat in velocity out to periods of $100 \mathrm{sec}$. Although an STS-1 would allow better resolution of long-period energy from the Denali event, there is no STS-1 within
$100 \mathrm{~km}$ of OCTRN and differing path effects would distort the GPS-seismometer comparison. No filtering of the displacement records was performed. Most of the seismic channels show maximum displacements of 10-20 mm, with the strongest motion appearing on the east-west horizontal component.

[10] Comparison of the GPS and seismic displacements are shown in Figures 2 and 3. In Figure 2, we show that the rms difference of the displacements of OEOC before spatial filtering relative to the seismic displacements of the closest seismic site PLS is $2.9 \mathrm{~mm}$ in the north component and $3.3 \mathrm{~mm}$ in the east component. After spatial filtering, the rms difference is reduced to $2.8 \mathrm{~mm}$ in the north component and $2.6 \mathrm{~mm}$ in the east component (Figure 3). The $1 \mathrm{~Hz}$ GPS horizontal displacements follow the seismic displacements (Love and Rayleigh waves) remarkably well in phase and amplitude over the period of about 700 seconds of dynamic motion. The amplitudes of the $\mathrm{P}$ and $\mathrm{S}$ waves are too small to be detected. The level of agreement is a factor of two better than the $6 \mathrm{~mm}$ precision expected from noise studies of instantaneous positions in static environments. A possible explanation for the overestimate of single-epoch precision is illustrated in Figure 4, which shows a longer time span of GPS data before and after the period of dynamic motion. It is apparent that the noise level of the GPS positions is actually improved during the dynamic phase, relative to the static periods. The primary noise contribution to instantaneous horizontal (and vertical) positioning at this
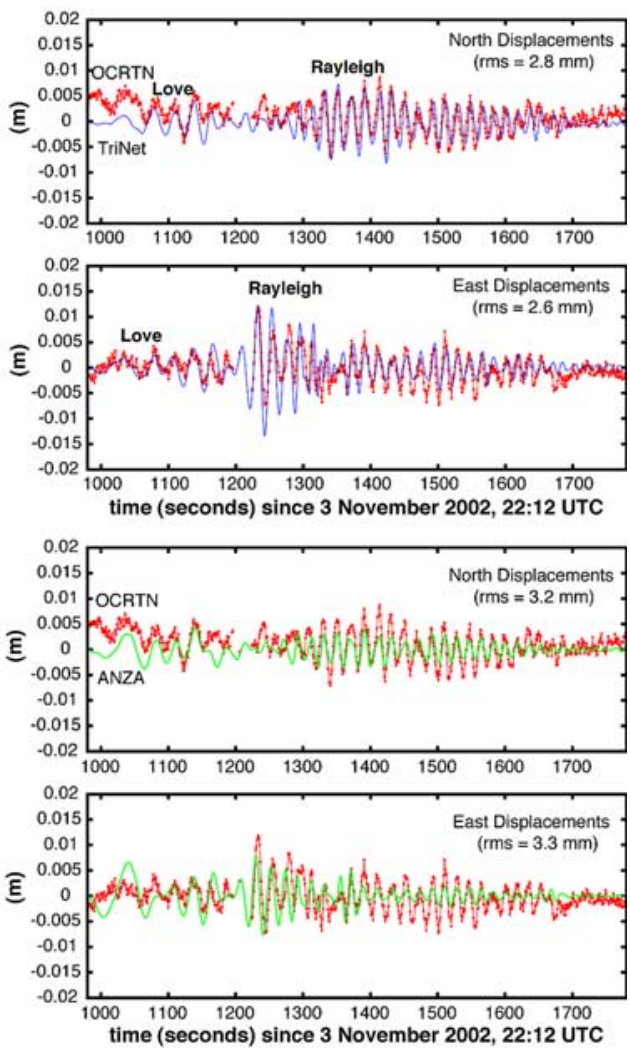

Figure 3. Same as Figure 2 except comparison of stacked horizontal displacements from 3 GPS stations (FVPK, OEOC, SBCC) and horizontal displacements from 2 seismic stations (TriNet site pls - upper two plots; ANZA site SMER - bottom two plots). 


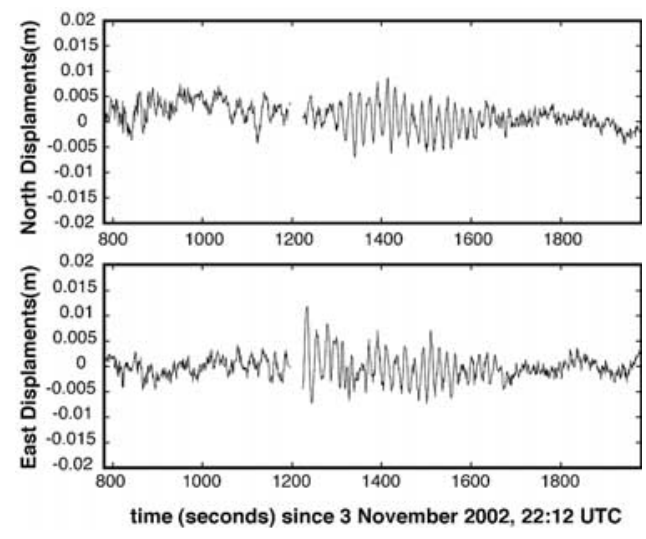

Figure 4. Same as Figure 3 except the spatially and sidereal-filtered GPS horizontal displacements are shown over a period that includes detectable seismic motions as well as preceding and later static periods.

spatial scale is signal multipath [Bock et al., 2000]. We postulate that the rapid position changes of the geodetic monument during the seismic period temporarily randomize the multipath effects and improve the measurement precision compared to the static periods. This is quite beneficial (and unexpected) since it implies that high-rate CGPS is more sensitive to displacements during periods of significant acceleration.

[11] The small $(\sim 10 \%)$ disagreements between the GPS and seismic displacements, although beyond the scope of this letter, could be due to a variety of factors, for example, uncertainties in the seismic gains, trans- $1 \mathrm{~Hz}$ energy in the waveforms that is being aliased by the GPS, site amplification differences between the TriNet/ANZA (seismic) and OCRTN (GPS) sites that are not strictly co-located (Figure 1), and the seismic motion of the site assumed fixed in the process of instantaneous positioning.

\section{Conclusions}

[12] The agreement between the GPS and seismic displacements demonstrates that besides measuring permanent surface deformation, high-rate (1 $\mathrm{Hz}$ or greater) GPS can clearly complement traditional seismology in the study of dynamic earthquake processes at regional and global scales. While the sensitivity of seismometers to strong ground motions is orders of magnitude greater than GPS, our results demonstrate that GPS can provide direct single-epoch measurements of ground motion with periods longer than $1 \mathrm{~s}$ and amplitudes greater than $\sim 2-3 \mathrm{~mm}$ with an inherent accuracy (signal to noise ratio) that increases indefinitely with dynamic displacement without clipping. The absolute displacements of the sites (with respect to ITRF2000) can be determined by using high-rate data from sites outside of the affected area.

[13] Instantaneous GPS provides independent position estimates at the receiver's sampling interval. Therefore, the technique is unaffected by cycle-slips, receiver losses of lock, and other technical considerations that adversely affect the application of traditional GPS survey and analysis methods to real-time ("on-the-fly") applications. Furthermore, instantaneous positioning is much less computationally intensive than multi-epoch static processing methods and can take advantage of the very high sampling rates provided by modern GPS receivers $(2-50 \mathrm{~Hz})$.

[14] The technique of GPS instantaneous positioning applied here to measuring seismic displacements (after the fact) can easily be adapted to real-time applications without loss of precision, and can take advantage of the very high sampling rates provided by modern GPS receivers (2$50 \mathrm{~Hz}$ ). The scientific rationale for high-rate, real-time GPS position data is diverse. For the OCRTN project, one group of scientists is interested in designing a displacement meter for early earthquake notification and seismic risk assessment based on an integration of GPS and seismic instrumentation, another group is interested in using the high-rate, real-time GPS data for intelligent transportation, while another is interested in near real-time atmospheric monitoring for short-term weather forecasting ("nowcasting"). Land surveyors have already begun using high rate $(1 \mathrm{~Hz})$ provided by OCRTN for performing routine high-accuracy $(1 \mathrm{~cm})$, low latency $(1-2 \mathrm{~s})$ positioning with significantly more efficiency and productivity than traditional GPS surveying methods [Andrew, 2003]. Furthermore, the same methodology is also well suited for other applications that have important societal and economic benefits, for example, public safety through airplane and harbor navigation; infrastructure location through geographical information systems; and structural tracking through building, bridge, and dam monitoring.

[15] Acknowledgments. We thank SCIGN, IGS and the TriNet and Anza projects for the use of GPS and seismic data, John Canas, Art Andrew, Glen Offield, Yolanda Radig and Frank Vernon for their valuable assistance, John Langbein for results from the Parkfield network, and three anonymous reviewers. The OCRTN was funded by NOAA's National Geodetic Survey through the JIMO program, and is a collaborative effort of the California Spatial Reference Center (CSRC), SCIGN, and Orange County's Public Resources and Facilities Division. Use of the Geodetics, Inc. RTD software for this project was provided by UCSD.

\section{References}

Altamimi, Z., P. Sillard, and C. Boucher (2002), ITRF2000: A new release of the International Terrestrial Reference Frame for earth science applications, J. Geophys. Res., 107(B10), 2214, doi:10.1029/2001JB000561.

Andrew, A. (2003), Real-time reality, Point Beginning, 28(11), 20-23.

Bock, Y., R. M. Nikolaidis, P. J. de Jonge, and M. Bevis (2000), Instantaneous geodetic positioning at medium distances with the Global Positioning System, J. Geophys. Res., 105, 28,223-28,254.

Dragert, H., K. Wang, and T. James (2001), A silent slip event on the deeper Cascadia subduction interface, Science, 292, 1525-1528.

Eberhart-Phillips, D., et al. (2003), The 2002 Denali fault earthquake: A large magnitude, slip-partitioned event, Science, 300, 1113-1118.

Larson, K., P. Bodin, and J. Gomberg (2003), Using 1-Hz GPS data to measure deformations caused by the Denali Fault earthquake, Science, $300,1421-1424$

Melbourne, T. I., and F. H. Webb (2002), Precursory transient slip during the $2001 \mathrm{Mw}=8.4$ Peru earthquake sequence from continuous GPS, Geophys. Res. Lett., 29(21), 2032, doi:10.1029/2002GL015533.

Melbourne, T. I., F. H. Webb, J. M. Stock, and C. Reigber (2002), Rapid postseismic transients in subduction zones from continuous GPS, J. Geophys. Res., 107(B10), 2241, doi:10.1029/2001JB000555.

Nikolaidis, R. M., Y. Bock, P. J. de Jonge, P. Shearer, D. C. Agnew, and M. Van Domselaar (2001), Seismic wave observations with the Global Positioning System, J. Geophys. Res., 106, 21,897-21,916.

Silver, P. G., et al. (1999), A plate boundary observatory, IRIS Newsl., $X V I(2), 3,7-9$.

Y. Bock and L. Prawirodirdjo, Cecil H. and Ida M. Green Institute of Geophysics and Planetary Physics, Scripps Institution of Oceanography, La Jolla, CA 92093, USA. (ybock@ucsd.edu)

T. I. Melbourne, Department of Geological Sciences, Central Washington University, Ellensburg, WA 98926, USA. 